\title{
Gestão do uso do solo no entorno do Rio Sapucaí em Itajubá (MG)
}

Land use management in the surroundings areas of the Sapucaí River in Itajubá-MG

Raquel Regina de Oliveira Martins Felix[a], Viviane Alves ${ }^{[a]}$, Josiane Palma Lima[a]

[a] Universidade Federal de Itajubá (UNIFEI), Itajubá, MG, Brasil

Como citar: Felix, R. R. O. M., Alves, V. \& Lima, J. P. (2019). Gestão do uso do solo no entorno do Rio Sapucaí em Itajubá (MG). urbe. Revista Brasileira de Gestão Urbana, 11, e20170180. https://doi.org/10.1590/2175-3369.011.001.A002

\section{Resumo}

A expansão urbana no município de Itajubá (MG) ocorreu em áreas onde atualmente o Código Florestal visa proteger, denominadas áreas urbanas de ocupação consolidadas. Porém, a carência de dados específicos da região dificulta a tomada de decisão dos gestores. Nesse contexto, este trabalho tem o objetivo de diagnosticar as áreas do município limítrofes ao Rio Sapucaí, com vista à gestão sustentável de uso e ocupação do solo. 0 estudo de caso aborda o ordenamento jurídico referente às áreas de preservação permanente (APP), do âmbito federal ao municipal, bem como as diretrizes do Plano Diretor. Foi realizado o mapeamento das áreas limítrofes ao rio, com o auxílio do Sistema de Informação Geográfica (SIG), por meio da interpretação visual de imagens de satélite georreferenciadas. A elaboração dos mapas possibilitou a classificação dessas áreas quanto ao uso e à ocupação, como também a preocupação em aumentar e manter áreas reflorestadas nos últimos dez anos pela administração municipal, além de constatar a existência de locais já adensados que poderiam receber projetos de revitalização e mobilidade visando à melhoria da qualidade de vida da população.

Palavras-chave: Uso do solo. Urbanização consolidada. APP urbana.

\section{Abstract}

The urban expansion in Itajubá-MG occurred in areas where the Forest Code currently purpose to protect, called consolidated urban areas of occupation. However, the failure of specific data in the region makes it difficult for managers to make a decision. In this context, this work objectives to diagnose in surrounding the Sapucaí River, with a view to the sustainable management of land use and occupation. The case study deals with the legal framework for the "Áreas de Preservação Permanente" (APP) from the Federal to the Municipal scope, as well as the directives of the Master Plan. The mapping the surround areas to the River was realized, with the support of the Geographic Information System (GIS), by visual interpretation of georeferenced satellite images. The mapping made it possible to classify these areas in terms of use and occupation, as well as the concern to increase and maintain areas reforested in the last ten years by the

RROMF é engenheira ambiental, mestre em Desenvolvimento, Tecnologia e Sociedade, e-mail: raquel_felix_unifei@yahoo.com.br VA é arquiteta e urbanista, mestranda em Desenvolvimento, Tecnologia e Sociedade, e-mail: viviane.arquitetura@yahoo.com.br JPL é doutora em Engenharia de transportes, professora associada, e-mail: jplima@unifei.edu.br 
municipal administration, besides to verify the existence of already densely populated sites that could receive revitalization and mobility projects to improve the quality of life of the population.

Keywords: Land use. Consolidated urbanization. Urban APP.

\section{Introdução}

O Estatuto da Cidade (Lei no 10.257/2001) apresenta instrumentos legais para implantação da gestão e transformação dos municípios brasileiros. As leis de uso e ocupação do solo e o Plano Diretor são ferramentas utilizadas para o planejamento urbano, auxiliando o poder público no atendimento às demandas da população e na tentativa de viabilizar o crescimento ordenado (Brasil, 2001; Machado \& Lima, 2015).

Anteriormente ao Estatuto da Cidade, foi criada, no âmbito federal, a Lei no 6.766/1979 que aborda diretrizes para o parcelamento do solo urbano. Porém, no município de Itajubá (MG), esse tema foi abordado somente em 1991 com a regulamentação da Lei Municipal no 1.774 (parcelamento do solo urbano) e da Lei Municipal no 1.988/1994, que estabelece regras para o uso e a ocupação do solo. Em razão do Estatuto da Cidade, as políticas de expansão urbana do município foram sendo desenvolvidas por meio da criação do Plano Diretor (Lei Complementar no 008/2003) (Brasil, 1979; Itajubá, 1991, 2003).

Muitas vezes, o processo de urbanização ocorre de forma desordenada, colocando em dúvida a eficácia do planejamento, que, nesses casos, acontece sem o rigor da legalidade, de acordo com as circunstâncias e às vezes até por interesses políticos. Um dos exemplos é a ocupação desordenada das áreas de várzea no entorno dos rios - regiões atualmente consideradas áreas de preservação permanente (APPs), amparadas no Código Florestal (Lei Federal no 12.561/2012) - que compromete a capacidade ambiental dos recursos naturais e, consequentemente, o equilíbrio ambiental (Bressane et al., 2010; Brasil, 2012).

Contudo, deve-se considerar que a expansão do município ocorreu em áreas onde o Código Florestal visa proteger, bem como garantir a ocupação em áreas que apresentam infraestrutura mínima já instalada, denominadas áreas urbanas de ocupação consolidadas. A ocupação desordenada pode também ocorrer em razão da negligência da fiscalização no contínuo movimento de expansão do município, assim como pela insuficiência de informações concisas e atualizadas sobre o real uso e ocupação do solo urbano. Porém, não faz parte do escopo deste trabalho investigá-las.

A carência de dados dificulta a tomada de decisão dos gestores públicos, na medida em que acompanhar e controlar essa expansão urbana se torna cada vez mais necessário. Nos últimos anos, as geotecnologias têm sido utilizadas como ferramentas de apoio à tomada de decisões, pois possibilitam analisar o ambiente de forma sistêmica. Assim, o geoprocessamento é amplamente visto como um aliado no planejamento urbano, uma vez que possibilita a integração das diversas variáveis envolvidas, elaborando diagnósticos das reais situações do ambiente, auxiliando nas propostas de soluções viáveis (Mehra et al., 2017; Sánchez-Lozano \& Bernal-Conesa, 2017; Gurgel et al., 2017; Kar et al., 2018). 0 monitoramento da expansão urbana ajuda a identificar as áreas onde os recursos ambientais e naturais são criticamente ameaçados. 0 uso de geotecnologias auxilia o mapeamento das áreas urbanas, tanto para diagnóstico quanto para a sua importância na gestão do uso e ocupação do solo (Netto \& Krafta, 2009; Limonad et al., 2014; Gurgel et al., 2017; Mehra et al., 2017; Sánchez-Lozano \& Bernal-Conesa, 2017).

Nesse contexto, este trabalho tem o objetivo de diagnosticar as áreas limítrofes ao rio Sapucaí no município de Itajubá (MG), com vista à gestão sustentável do uso e ocupação do solo. Com o auxílio de um Sistema de Informação Geográfica (SIG), foram identificadas áreas de proteção e também outras propensas a receber projetos de revitalização e mobilidade urbana visando à melhoria da qualidade de vida da população. 


\section{Gestão sustentável do uso e ocupação do solo}

A gestão sustentável de áreas urbanas voltada ao controle de uso e ocupação do solo é um processo de extrema importância, auxiliando na expansão racional e nas questões sociais e ambientais. 0 plano diretor municipal é instrumento fundamental para orientar a ação dos agentes em prol do desenvolvimento urbano equilibrado (Honda et al., 2015). Entretanto, muitos dos problemas urbanos resultam da falta de rigor na fase de implementação das propostas contidas no Plano Diretor (Angeoletto et al., 2016; Requia et al., 2016). Embora, no Brasil, as questões sociais e ambientais tenham atingido importância na sociedade civil, ainda é dada pouca prioridade a esses problemas em âmbito municipal, talvez pela pouca presença efetiva da população nas tomadas de decisão (Maricato, 2006; Moscarelli \& Kleiman, 2017). Além do Plano Diretor, o Estatuto da Cidade (Lei Federal no 10.257/2001) tenta suprir a necessidade de democratização da gestão urbana, enfatizando a função social da cidade e a ampliação dos espaços de participação social.

O Instituto Brasileiro de Geografia e Estatística (IBGE) aponta que em 1940 a taxa de urbanização era de pouco mais de $30 \%$, tendo passado para $84,36 \%$ em 2010 e com perspectiva de atingir $90 \%$ em 2020 (IBGE, 2010). 0 rápido crescimento das cidades levantou várias preocupações, principalmente nas de pequeno e médio portes, onde o crescimento foi mais acelerado e a capacidade de planejamento e gerenciamento não consegue acompanhar tal fato, o que também é observado no município de Itajubá (MG). Historicamente, houve a tentativa de se atender às necessidades da população das áreas residenciais, levando, então, serviços públicos. Porém, as áreas com menos importância econômica, desde sempre, são excluídas desse desenvolvimento. Essas extensões da cidade foram parceladas e ocupadas sem considerar padrões de qualidade ambiental, regulamentações urbanísticas ou quaisquer outras regras que garantam ao proprietário o direito legal à propriedade. 0 modelo de ocupação do solo desordenado compromete a qualidade de vida da cidade (Carvalho, 2001; Rolnik, 2009).

Vários autores concordam que a eficácia do planejamento urbano, ou a gestão urbana sustentável, está associada a uma mudança de paradigma, em que não basta mais elaborar soluções individuais para problemas interligados, uma vez que requer elevado potencial de dinamismo e transformação, devendo ser tratada de maneira sistêmica (Arefiev et al., 2015; Lombardi \& Ferretti, 2015; Kar et al., 2018).

A gestão sustentável enfatiza o equilíbrio entre os diversos problemas do meio urbano. Trata-se de um processo complexo que deve ser considerado de forma interdisciplinar, ou seja, abordando os três pilares da sustentabilidade (vitalidade econômica, proteção ambiental e equidade social). As estratégias mais comuns em busca da sustentabilidade urbana são aquelas que giram em torno da preservação dos espaços verdes, desenvolvimento do espaço público, estratégias habitacionais e desenvolvimento orientado para o transporte sustentável (DOTS) (Nasri \& Zhang, 2014; Requia et al., 2016). Alguns estudos mais específicos abordam a melhoria das condições de acessibilidade da população aos setores dos quais ela necessita (segurança, educação, saúde, serviços) e, consequentemente, contribuem para a qualidade de vida (Silva et al., 2008; Hassan \& Lee, 2015; Sakamoto \& Lima, 2016).

Contudo, vários estudos buscam meios e técnicas de amenizar os efeitos do processo de urbanização desordenada, tentando encontrar um equilíbrio entre meio ambiente, sociedade e economia (Bispo \& Levino, 2011; Buhaug \& Urdal, 2013; Wan et al., 2015). Porém, por exemplo, seria ideal se as cidades fossem igualitárias em termos de acesso aos equipamentos públicos ou se as áreas limítrofes aos recursos hídricos que passam pelas regiões urbanas e adensadas tivessem seus entornos intactos e preservados, fato que não ocorre na maioria das cidades brasileiras, que foram urbanizadas no entorno de rios e afluentes. Nesse sentido, o papel do planejamento urbano se expande e ganha cada vez mais força no caminho de reconstituir, revitalizar e alcançar uma cidade sustentável. A revitalização do meio urbano se torna uma estratégia importante de gestão do uso e ocupação do solo, com ênfase na manutenção das estruturas urbanas em condições que satisfaçam às exigências das atividades de habitação, trabalho, circulação e lazer, evidenciando as necessidades de mobilidade da população nas estratégias de gestão do espaço urbano (Waddell, 2011; Cervero, 2013; Litman, 2017; Mello \& Portugal, 2017). 


\section{Itajubá e o Rio Sapucaí}

O município de Itajubá está situado na Serra da Mantiqueira, no sul do estado de Minas Gerais, atingindo a altitude de 1.746 metros no seu ponto mais alto e de 830 metros no ponto mais baixo. Sua área urbana encontra-se na altitude média de 842 metros, com $294,83 \mathrm{~km}^{2}$ de extensão, sendo $254,03 \mathrm{~km}^{2}$ de área rural e 40,80 km² urbanizada. A população é de 90.658 habitantes, numa taxa anual de crescimento de 1,26\% habitante por ano (IBGE, 2010).

Assim como em diversos municípios, o histórico da ocupação em Itajubá iniciou-se às margens dos rios, principalmente em razão da topografia local que, segundo o IBGE (2010), é caracterizada como ondulada montanhosa: $10 \%$ plana, $12 \%$ ondulada e $78 \%$ montanhosa. Contudo, o município é favorecido em relação à sua localização devido à sua posição em relação às grandes capitais da região Sudeste: Belo Horizonte (445 km), São Paulo (261 km) e Rio de Janeiro (318 km) (Barbosa et al., 2015).

A história da fundação de Itajubá se diferencia das demais cidades das regiões vizinhas, pois não está relacionada a nenhum bandeirante nem à permanência de desbravadores em suas terras atrás de ouro. A ocupação da região itajubense em meados de 1819 se deu pela instalação de habitantes do povoado vizinho que estavam à procura de melhores condições para o plantio de alimentos para a sobrevivência. A expansão da cidade fundamentou-se no entorno do Rio Sapucaí, aproveitando a planície do rio para consolidar o desenvolvimento do município, como pode ser observado na Figura 1 (Guimarães, 1987).

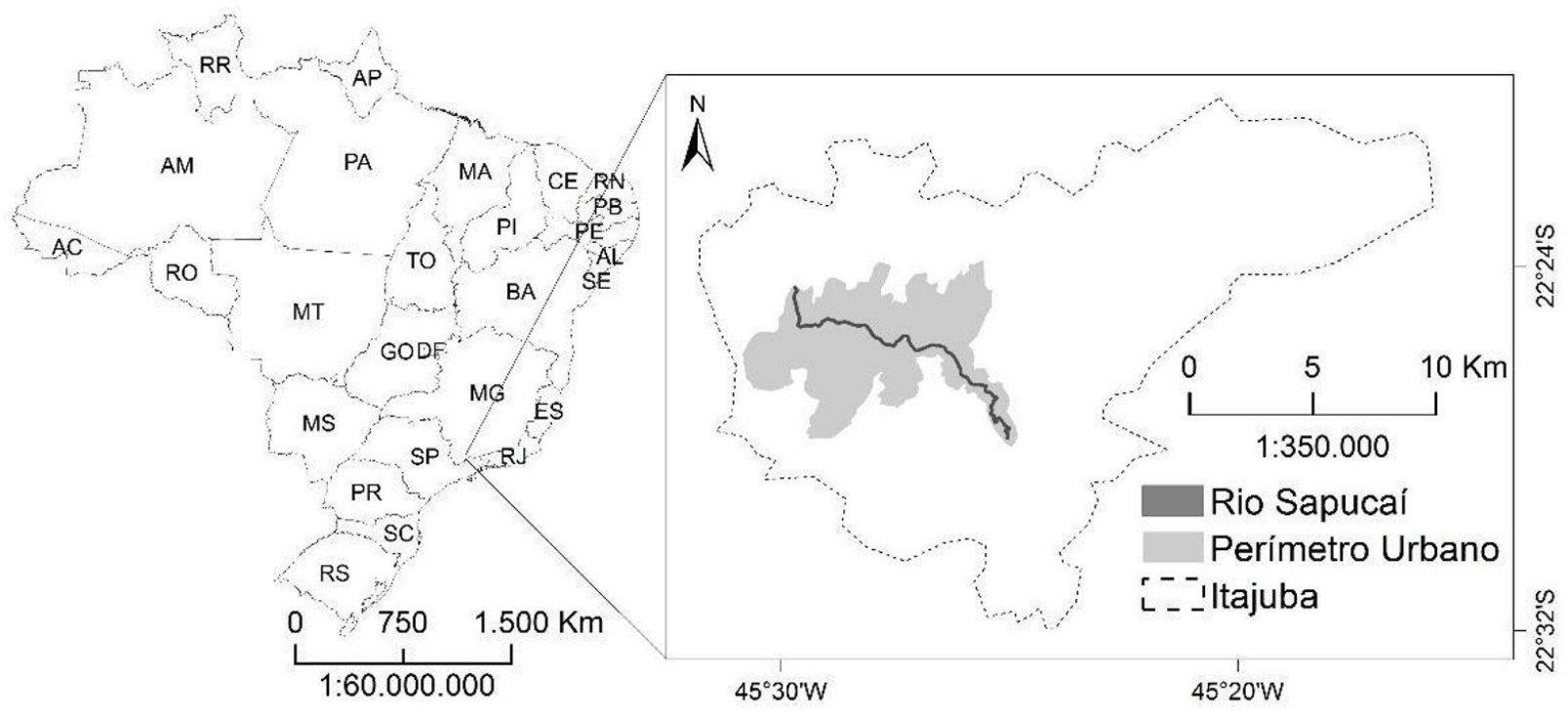

Figura 1 - Mapa de localização da região do município de Itajubá/MG.

O Rio Sapucaí nasce na Serra da Mantiqueira, no município de Campos de Jordão (SP), a aproximadamente 1.700 metros de altitude, e desagua no Rio Grande a aproximadamente 780 metros de altitude. 0 rio tem grande importância para a região, uma vez que transpassa $120 \mathrm{~km}$ entre os estados de São Paulo e Minas Gerais. 0 trecho do rio que corta o município de Itajubá está localizado na Bacia do Alto Sapucaí e sua área de drenagem desde a nascente até a região estudada tem aproximadamente $1.000 \mathrm{~km}^{2}$ (Guimarães, 1987).

\section{Aspectos legais para a gestão do uso do solo}

De acordo com a Constituição Federal de 1988, estabelecer critérios para a gestão do solo urbano é tarefa da legislação municipal de uso e ocupação do solo, em especial do Plano Diretor. 0 artigo 30, VIII, da Carta Magna, determina aos municípios a competência de promover, quando couber, adequado 
ordenamento territorial, mediante planejamento e controle do uso, do parcelamento e da ocupação do solo urbano (Brasil, 1988).

Anteriormente à Constituição, o governo federal instituiu a Lei no 6.766 que discorre sobre o parcelamento do solo urbano. Nela é citada a criação do cadastro de áreas de risco e inundações nos municípios brasileiros, porém muitos ainda não estão inscritos nesse cadastro, o que dificulta o monitoramento dessas áreas, como é o caso da situação itajubense, onde as áreas estudadas neste artigo deviam já estar cadastradas como áreas de risco.

A partir da década de 1990 foram promulgadas leis que caracterizam parcelamento e uso e ocupação do solo no município de Itajubá. Destacam-se as seguintes leis e as determinações das áreas non aedificandi das margens dos rios:

a) Lei Municipal no 1.774/1991 - dispõe sobre o parcelamento do solo urbano - 0 art. 6ำ define como área não edificante as margens do Rio Sapucaí a distância de 30 metros a partir da margem em ambos os lados (Itajubá, 1991);

b) Lei Municipal no 1.988/1994 - dispõe sobre zoneamento e regulamenta o uso do solo nas diversas zonas do perímetro urbano do município de Itajubá - 0 art. 17ํ define como área não edificante as margens do Rio Sapucaí a distância de 15 metros, caracterizado pela zona de proteção ambiental (ZPA) (Itajubá, 1994);

c) Lei Complementar 008/2003 (Plano Diretor) - 0 art. 44o caracteriza o Eixo do Sapucaí, que se refere às áreas destinadas à reurbanização das faixas ao longo do Rio Sapucaí. Prevê a instalação de avenidas marginais e o reaproveitamento de áreas lindeiras, conciliando a presença dos usos diferenciados. 0 art. 46o também define a mesma área como AIA I - Área de Interesse Ambiental I -, as áreas destinadas à proteção das margens dos cursos d'água, sendo no perímetro urbano a distância de 50 metros no mínimo para o Rio Sapucaí e permitindo a distância de 15 metros para efeitos de desapropriação (Itajubá, 2003).

Com a promulgação da Lei Federal no 10.257, de 10 de julho de 2001, denominada Estatuto da Cidade, tornaram-se obrigatórias a elaboração e a implantação do Plano Diretor em municípios com mais de 20 mil habitantes. Entretanto, em Itajubá, apenas em 2003 ele foi desenvolvido, mesmo contendo polução superior ao limite mínimo estabelecido para a criação do Plano Diretor. Ainda assim, suas diretrizes somente foram respeitadas e empregadas a partir de 2012, depois de se suspeitar do descumprimento dessas leis e devido a exigências do Ministério Público no município (Brasil, 2001).

Ressalta-se que o Plano Diretor (Lei Complementar Municipal no 008/2003) não revogou as leis de parcelamento de solo (Lei Municipal no 1.774/1991) e lei de uso e ocupação do solo (Lei Municipal no 1.988/1994), tornando-as, portanto, atuantes até a presente data. Entretanto, a lei de uso e ocupação do solo foi aplicada integralmente até o ano 2012 quando houve a obrigatoriedade da aplicação do Plano Diretor, como supracitado.

Entretanto, enquanto a Lei Federal de Parcelamento de Solo (Lei Federal no 6.766/1979) é constantemente atualizada mediante a inclusão e o revogamento de artigos, destacando a importância das diretrizes dos Planos Diretores Municipais para o ordenamento territorial local, a Lei Municipal de Parcelamento de Solo (Lei Municipal no 1.774/1991) permanece sem alterações, ocasionando incongruências com o Plano Diretor vigente. Um exemplo é a duplicidade de definições referentes à área não edificada ao longo do Rio Sapucaí: largura de 30 metros em cada margem, conforme a Lei de Parcelamento do Solo, e largura de 50 metros em cada margem, conforme o Plano Diretor Municipal.

\section{Delimiłação da área de estudo}

0 objeto de estudo foi definido pela área delimitada por um buffer, de raio de 50 metros, a partir das margens do Rio Sapucaí que se encontram dentro do limite urbano do município de Itajubá (MG) (Figura 2). A escolha da área foi baseada na importância histórica de ocupação desordenada que se 
consolidou no entorno desse rio, bem como nas características presentes no ordenamento jurídico vigente. De acordo com o Código Florestal Brasileiro (Lei Federal no 12.651, de 25 de maio de 2012), a delimitação da APP nas faixas marginais para o Rio Sapucaí é de 50 metros a partir da borda da calha do leito regular, admitindo que a largura média entre as bordas se enquadra na faixa de 10 a 50 metros (Brasil, 2012).

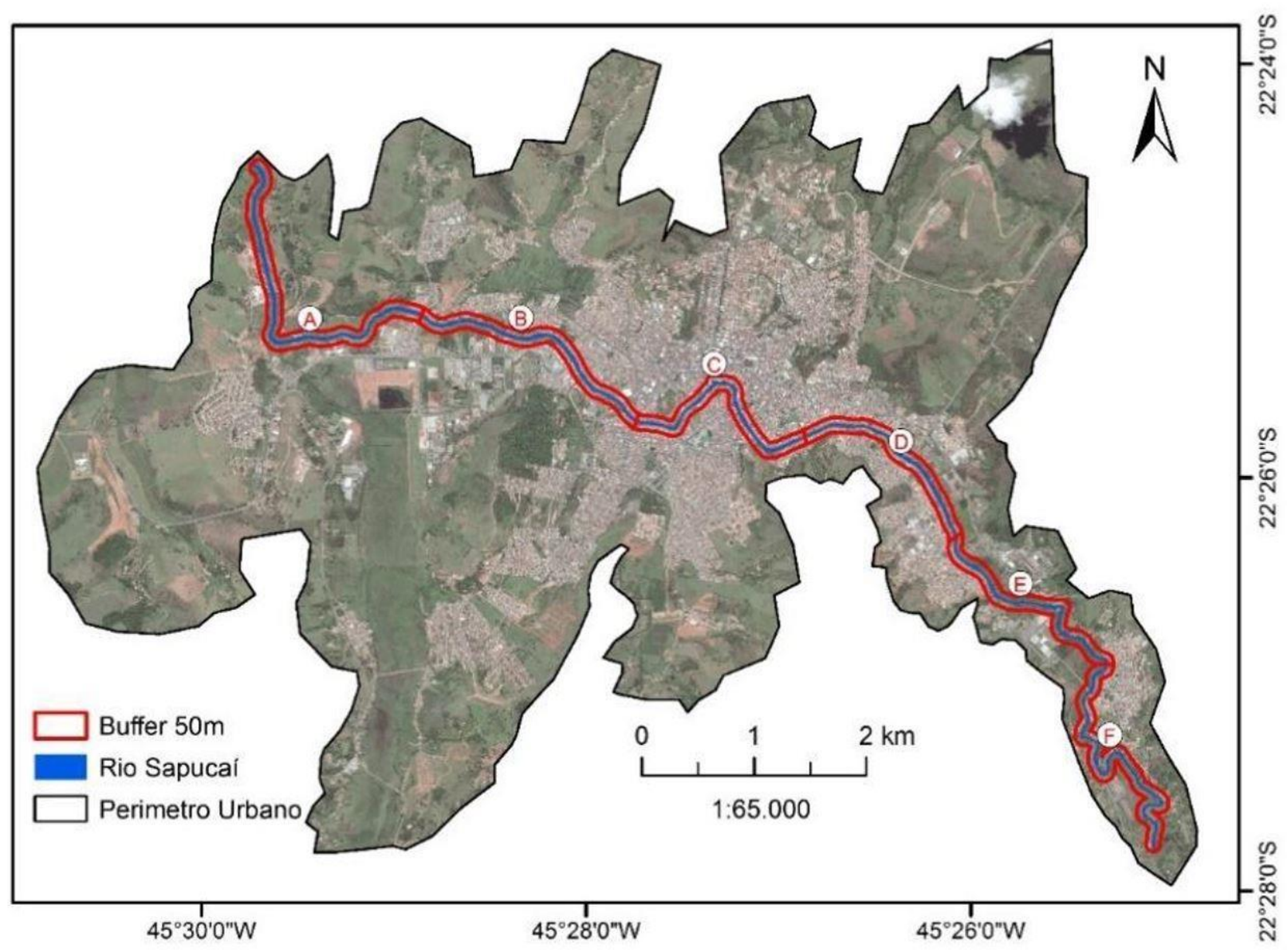

Figura 2 - Área de estudo: entorno do Rio Sapucaí - Itajubá/MG.

Entretanto as leis municipais (no 1.774/1991 e no 1.988/94) anteriores ao Plano Diretor estabeleciam limites inferiores ao atual de 50 metros (respectivamente, 30 metros e 15 metros) para as áreas do entorno do rio dentro do perímetro urbano. Logo, para uma posterior análise histórica da ocupação, foram adicionados ao banco de dados dois buffers, um com raio de 15 metros e outro de 30 metros, a partir da margem do Rio Sapucaí (Itajubá, 1991, 1994).

\section{Diretrizes do Plano Diretor para zoneamento, uso e ocupação do solo no município}

Com base na pesquisa do ordenamento jurídico, foi possível constatar as seguintes diretrizes para a área de estudo. No Plano Diretor, é descrito o zoneamento que caracteriza especificamente a área de estudo, denominado área de interesse urbanístico (AIU), e corresponde às áreas de intervenção específicas com o intuito de melhorar a infraestrutura urbana. Esse zoneamento é subdividido em AIU I - destinada ao Eixo Sapucaí com a finalidade de implantar projetos de reurbanização ao longo do Rio; AIU II - destinada a implantar equipamentos urbanos e instalar centros de serviços e comércio regional; AIU III - destinada a implantar equipamentos institucionais e de serviços incompatíveis com o uso urbano (Itajubá, 2003). 
A AIU I, definida como áreas ao longo do Eixo Sapucaí, caracterizada pela faixa a partir de 50 metros da margem do Rio Sapucaí, também é citada no Plano Diretor no art. 92º Cap. 9 - diretrizes para parcelamento do solo -, o qual define esse mesmo perímetro com base no Decreto Estadual no 33.944, de 18 de novembro de 1992, que regulamenta a Lei Estadual no 10.561, de 27 de dezembro de 1991, o qual trata sobre a Política Florestal no estado de Minas Gerais (1991).

Contrapondo essa interpretação, o Plano Diretor apresenta, no art. 44ํㅜ, o mesmo que caracteriza a AIU, a definição de que, no caso da não elaboração do projeto de reurbanização, serão apenas permitidas ou admitidas obras de manutenção e não poderão ser ocupadas as áreas vagas não edificáveis previstas em leis na margem do Rio Sapucaí, tão pouco a emissão de alvará de funcionamento para estabelecimentos industriais, comerciais ou de serviços. Porém, não são definidas no Plano Diretor as características da área de ocupação consolidada, sendo necessário recorrer a definições existentes em diferentes legislações que a contemplem. Assim, o Código Florestal traz no art. 4oㅡ, ins. V, § 9o a delimitação das áreas de preservação permanentes em áreas urbanas, porém vetado e instituído pela Lei Federal no 12.727, de 17 de outubro de 2012, na qual faz referência à definição de área de ocupação consolidada descrita pela Lei Federal no 11.977, de 7 de julho de 2009. Esta possui uma interpretação controversa do Código Florestal, pois, no art. 47ํㅡㄹ inc. II, permite a ocupação de áreas limítrofes aos rios onde já exista infraestrutura urbana mínima consolidada, permitindo, assim, novas ocupações. Essa incongruência entre essas leis dificulta o controle do adensamento urbano nessas regiões, já que ocasiona uma ambiguidade sobre a legalidade ou não de determinadas ocupações (Brasil, 2012).

A partir do conjunto de normas legais vigentes no período de estudo, as quais afetam o uso e a ocupação do solo do município de Itajubá, foi elaborada uma classificação do uso do solo própria para avaliar a expansão urbana.

Definiram-se as seguintes categorias para geração dos mapas:

- Residencial: construções com atributos exclusivos para moradia;

- Institucional: instalações ou espaços destinados a receber público;

- Local: administração pública, escolas, creches, universidades, postos de saúde, assistência social, espaços culturais, religiosos, lazer e segurança pública (exceto aquelas previstas como serviços especiais);

- Geral: aqueles que não compreendem o uso local, porém recebem público (exceto aquelas previstas como serviços especiais).

- Comércio e serviços: construções ou áreas que exclusivamente são instalações de atendimento geral ou local, que se destinam ao comércio e à prestação de serviços;

- Industrial: construções ou áreas com instalações que tenham qualquer tipo de processo produtivo em massa;

- Misto: construções que compreendem em um mesmo imóvel duas ou mais categorias aqui descritas;

- Sistema viário: traçado que engloba o eixo viário e calçadas;

- Área verde: áreas ainda conservadas ou reflorestadas com mata adensada;

- Lote vago: áreas ainda não edificadas, desertificadas ou com vegetação rasteira;

- Serviços especiais: serviços causadores de impactos ao meio ambiente urbano, sendo passível de licenciamento de operação e implantação aprovados pelos órgãos competentes.

As diretrizes de uso e ocupação do solo e a relação com cada tipo de zoneamento se encontram dispostas no Plano Diretor de 2003, Anexo I.II (adaptada na Tabela 1). Dos zoneamentos apontados, é pertinente apenas ressaltar os diferentes usos do solo na área de estudo, aqueles inseridos na AIU I - Área de Interesse Urbanístico do Eixo do Sapucaí. 
Tabela 1 - Zoneamento, uso e ocupação do solo admitidos

\begin{tabular}{lcccccc}
\hline \multirow{2}{*}{ Residencial } & \multirow{2}{*}{ Comércio e serviço } & \multicolumn{2}{c}{ Institucional } & \multirow{2}{*}{ Industrial } & \multirow{2}{*}{ Misto } \\
\cline { 3 - 5 } & & Local & Geral & & \\
\hline AlUI & Admite uso & Admite uso & Admite uso & Não admite uso & Não admite uso & Admite uso \\
\hline
\end{tabular}

AlU I = Área de Interesse Urbanístico do Eixo do Sapucaí. Fonte: Plano Diretor (Itajubá, 2003) do município de Itajubá (MG) adaptado pelo autor.

Assim, da Tabela 1 é possível notar que apenas os usos industrial e institucional geral não são admitidos pelo Plano Diretor vigente, sendo os demais usos do solo descritos sujeitos à aprovação de projetos, desde que cumpridos todos os parâmetros urbanísticos para tal uso.

Então, definidas as classes de uso do solo e o zoneamento pertinente, foram diagnosticados polígonos para cada uso e ocupação dentro da região estudada, com o auxílio do sensoriamento remoto e os Sistemas de Informações Geográficas (SIG), que possibilitam o georreferenciamento das informações. O uso de SIG representa um importante suporte para o planejamento e tomadas de decisões, visto que essa ferramenta permite análises complexas ao integrar dados de diversas fontes e ao criar um banco de dados georreferenciado (Câmara et al., 2001).

Para delimitar os polígonos, foi utilizada a imagem base obtida pelo satélite Worldview 2, modo cor natural (RGB + PAN), com 50 cm de resolução espacial, projeção UTM e Datum WGS84, adquirida em 24 de novembro de 2011. A área estudada que compõe a imagem de 2011 foi definida considerando o perímetro urbano do município, disposto no Plano Diretor (Itajubá, 2003). Com o auxílio dos softwares de pesquisa Google Earth Pro e Google Street View, que continham imagens recentes de 2014 da região estudada, foi possível diagnosticar com mais clareza e definição a situação das áreas do entorno do rio (Google, 2001; Google Maps, 2016).

A interpretação visual utilizando todos esses recursos e as observações a campo, para melhor constatação em alguns trechos, viabilizaram a elaboração dos mapas temáticos de uso e ocupação do solo, assim como possibilitaram traçar um comparativo histórico entre 2005 e 2014 da real situação da mata ciliar no entorno do Rio Sapucaí.

\section{Resultados}

\section{Uso e ocupação do solo no entorno do Rio Sapucaí}

Os resultados do diagnóstico do uso do solo estão apresentados nos mapas temáticos das regiões nomeadas de A a F. A localização de cada uma das cinco regiões do entorno do Rio Sapucaí encontra-se na Figura 2. A divisão da área de estudo nessas regiões foi necessária apenas para uma melhor visualização dos detalhes do diagnóstico do uso do solo no mapa.

A região A (Figura 3a) trata-se de uma área pouco adensada, localizada à jusante do Rio Sapucaí. Na região, foi observado o predomínio da classe "Área Verde" e verificada a presença de três indústrias, como de usinagem, madeireira e frigorífico. Essa região encontra-se próxima ao zoneamento denominado de "Zona de Empreendimento de impacto", o que justifica a instalação dessas indústrias num período anterior às diretrizes do Plano Diretor (Itajubá, 2003).

$\mathrm{Na}$ região B (Figura 3b) foram encontrados o uso "Residencial", porém houve predomínio de "Comércio e Serviços" nas margens próximas à BR 459, Av. Tancredo de Almeida Neves, importante Rodovia Federal que atravessa o município. Essa região tem grande fluxo de veículos e torna-se atrativa ao comércio e à prestação de serviços de diversos produtos.

Na região C (Figura 3c), foi observada a maior diversidade de tipos de uso do solo, em coerência entre o que é permitido no Plano Diretor e o histórico de adensamento do meio urbano, permitindo, assim, o acesso da população aos serviços necessários no cotidiano, como comércio em geral e serviços 
institucionais. Foi ressaltado, ainda, que em razão do adensamento da área central junto à porcentagem ampla de residências, comércio e serviços nas áreas do entorno ao Rio Sapucaí, tornam-se pertinentes os estudos para elaboração de projetos de revitalização das margens, como parques arborizados e incentivo à mobilidade sustentável (ciclovias e calçadas amplas).

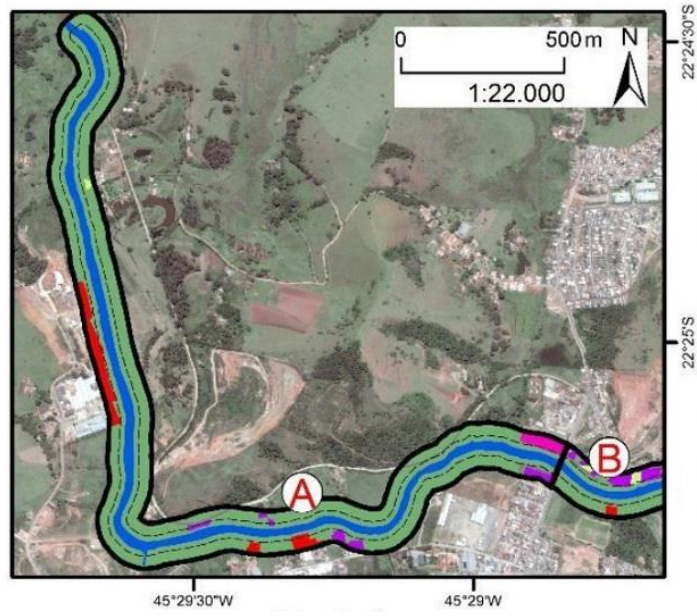

a) Região $\mathrm{A}$

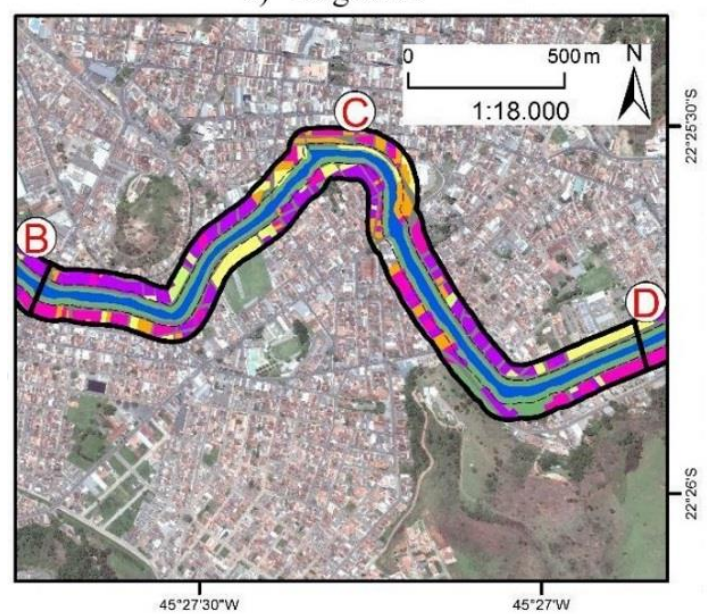

c) Região C

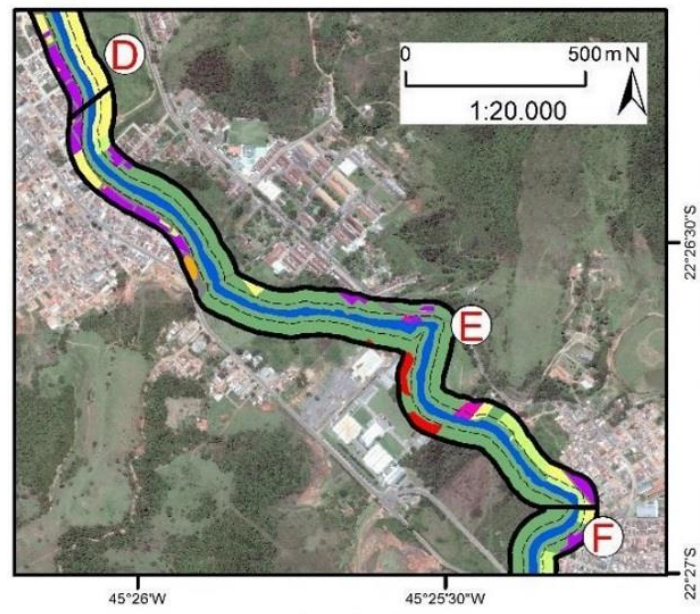

e) Região E

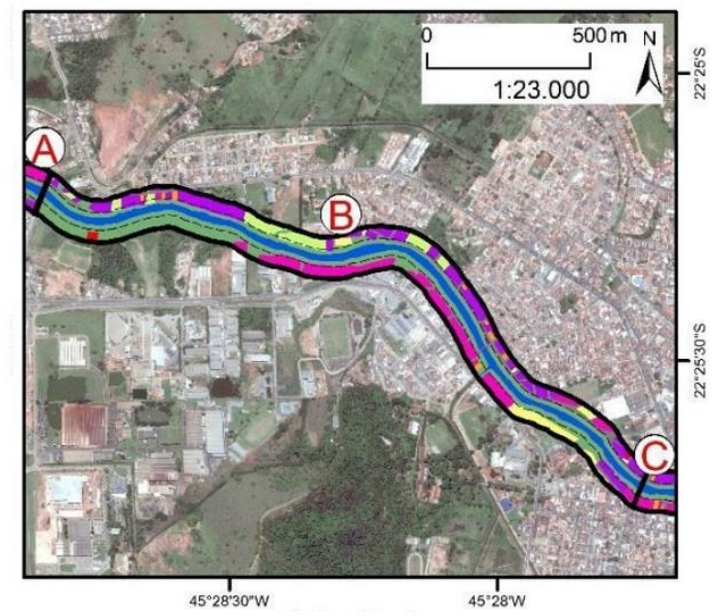

b) Região B

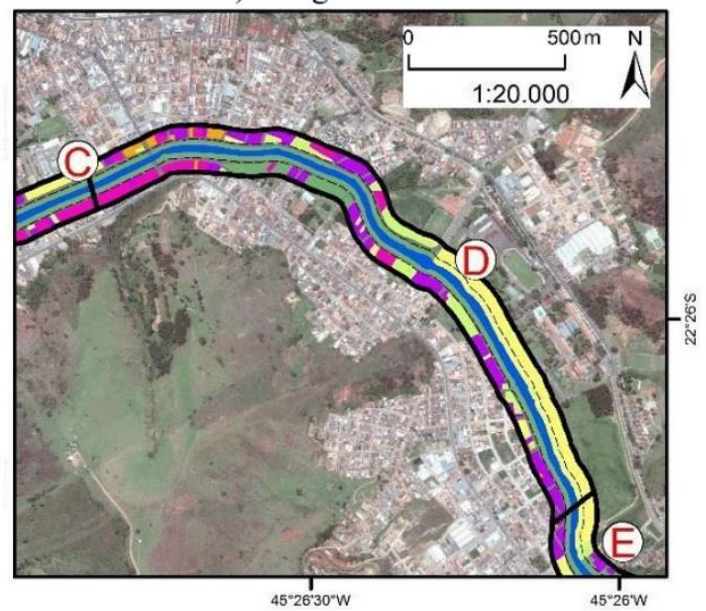

d) Região D

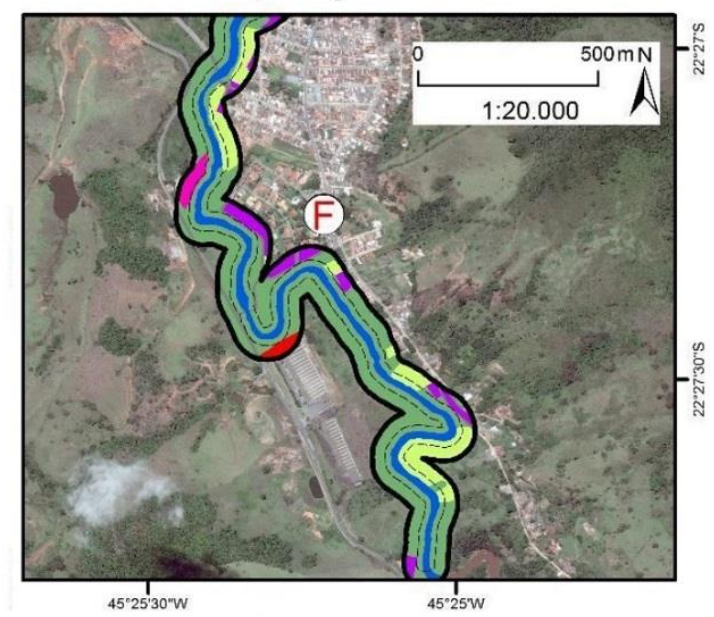

f)_Região F

\section{Legenda}

$\square$ Buffer 50m Misto Lote Vago Institucional $\quad$ Sistema Viário Serviços Especiais Buffer $15 \mathrm{~m} \square$ Industrial $\square$ Área Verde $\square$ Residencial $\square$ Rio Sapucaí $\square$ Comércio e Serviços

Figura 3 - Mapas de classificação do uso do solo. 
Também é de grande valia a reestruturação do sistema viário existente nas margens do rio na área central, visto o grande fluxo de veículos em horários de pico, pois auxiliaria no escoamento de veículos e possibilitaria a melhoria da infraestrutura para o transporte ativo, um meio extremamente comum na cidade, o qual não possui sua demanda suprida por falta de incentivo e investimentos do governo local. Os espaços religiosos foram classificados como uso institucional, por se tratar de instalações que recebem público. Porém, devido à falta de informações no Plano Diretor (art. 52, inc. IV), não é possível classificálos como de uso institucional local ou geral, embora os espaços religiosos representam $50,26 \%$ do total inserido no uso institucional.

Na região D (Figura 3d) foi destacada a presença do uso "Institucional" na margem esquerda do Rio Sapucaí, por se tratar das instalações do $4^{\circ}$ Batalhão de Engenharia de Combate de Itajubá, conhecido por Batalhão Pontoneiros da Mantiqueira. Na região E (Figura 3e) e na região F (Figura 3f), foram observadas uma homogeneidade de adensamento e a presença de grande área arborizada, sendo regiões em processo de expansão urbana. Estão caracterizadas próximas às zonas de adensamento do município e requerem planejamento efetivo para consolidar a urbanização de forma sustentável.

No gráfico apresentado na Figura 4, foi caracterizado o panorama das porcentagens e os valores em área para cada classe de uso do solo em toda a área de estudo definida anteriormente. 0 uso residencial apresenta-se com mais expressividade em toda a área estudada, em coerência com a admissibilidade do uso permitido pelo Plano Diretor (Itajubá, 2003).

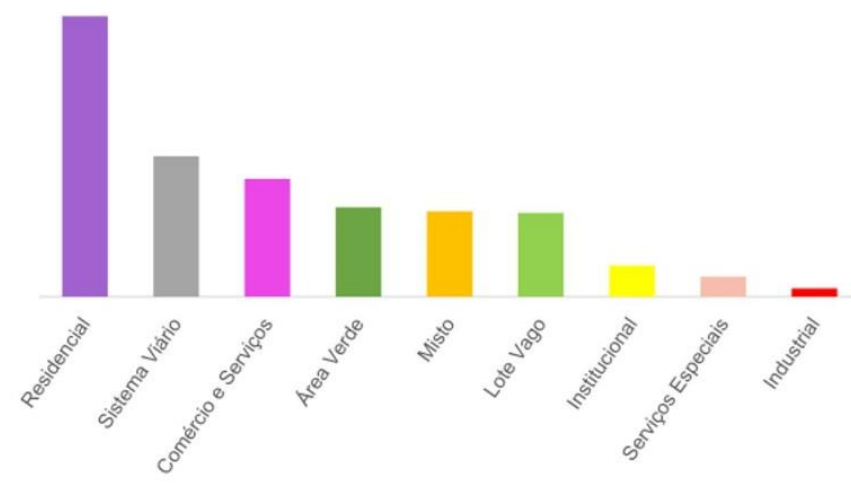

Figura 4 - Quantitativo de área (km² e porcentagem) dos diversos usos do solo. Fonte: Próprio autor (2017).

Os usos institucional geral, industrial e serviços especiais apresentam, juntos, representatividade insignificante $(6,96 \%)$ da área total, quando comparados aos demais usos do solo. Porém, há de se considerar que as instalações classificadas dentro desses usos foram admitidas em épocas anteriores, como a Lei Municipal no 1.988/1994, que permitia nas vias marginais do Rio Sapucaí a ocupação de residências uni e multifamiliares, comércio, serviços, institucional e industrial categoria I (pequenas indústrias que não causam danos, incômodos, nem representam perigo à população e ao meio ambiente) (Itajubá, 1994).

Os espaços religiosos foram classificados como uso institucional, por se tratar de instalações que recebem público. Porém, devido à falta de informações no Plano Diretor (art. 52, inc. IV), não é possível classificá-los como de uso institucional local ou geral, embora os espaços religiosos representam 50,26\% do total inserido no uso institucional (Itajubá, 2003).

Ressalta-se, ainda, que em razão do adensamento da área central, junto à porcentagem ampla de residências, comércio e serviços nas áreas do entorno ao Rio Sapucaí, tornam-se pertinentes os estudos para elaborar projetos de revitalização das margens, como parques arborizados e incentivo à mobilidade sustentável (ciclovias e calçadas amplas).

Também é de grande valia a reestruturação do sistema viário existente nas margens do rio na área central, visto o grande fluxo de veículos em horários de pico, pois auxiliaria no escoamento de veículos e possibilitaria a melhoria da infraestrutura para o transporte ativo, um meio extremamente comum na cidade, o qual não possui sua demanda suprida por falta de incentivo e investimentos do governo local. 
O Plano Diretor reafirma a importância do planejamento sustentável no art. 44, inc. I, determinando a área do entorno como elemento articulador de transformações para melhoria e ampliação dos espaços públicos de qualidade, a fim de integrar a população, proporcionando segurança e aumento da qualidade de vida (Itajubá, 2003).

\section{Histórico da recuperação da mata ciliar}

A partir do mapeamento da área de estudo, observou-se que a distância de 15 metros da margem do rio não foi edificada, mas sim ocupada apenas pelo sistema viário de baixo impacto e permanecendo preservada ou restaurada em quase toda a sua totalidade na área urbana. A fim de identificar a transformação ao longo dos anos para três (A, C e F) dos trechos em destaque no estudo, selecionaram-se imagens do Google Earth de 2005 e 2014 (Figura 5). Assim, pode ser constatada uma evidente recuperação da mata ciliar pela maior densidade de área verde no entorno do Rio Sapucaí.

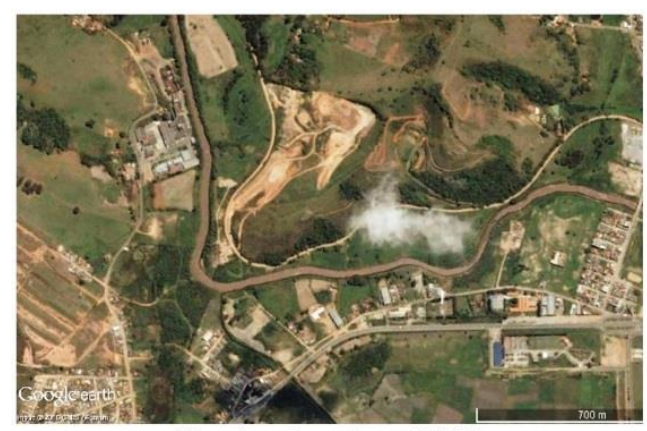

Trecho A - Ano 2005
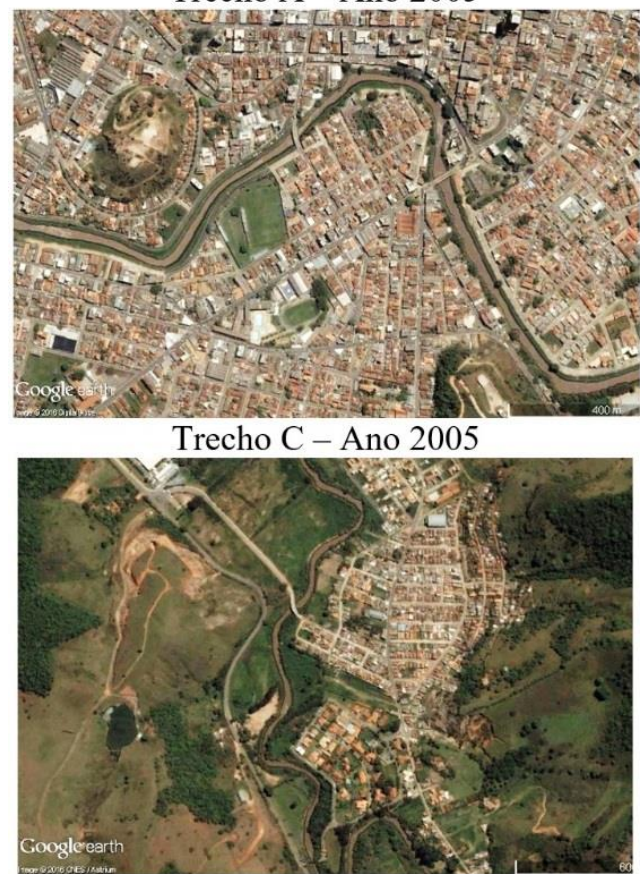

Trecho F - Ano 2005

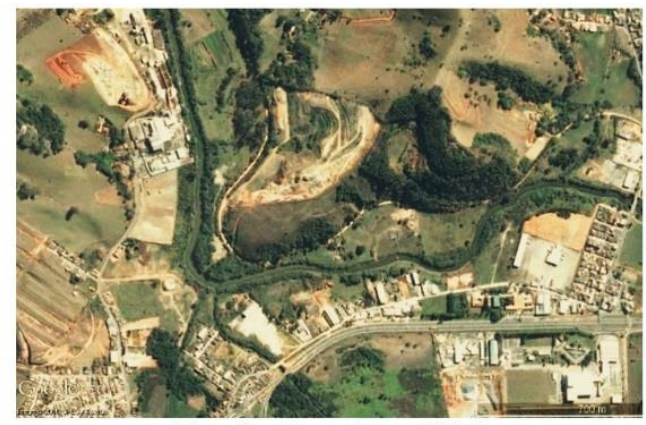

Trecho A - Ano 2014

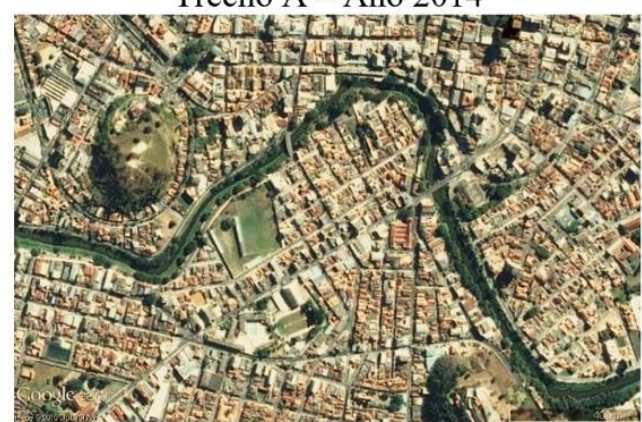

Trecho C - Ano 2014

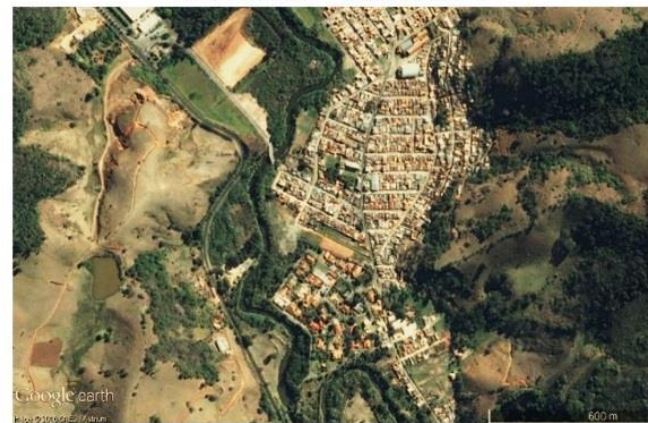

Trecho F - Ano 2014

Figura 5 - Evolução histórica da restauração da mata ciliar. Fonte: Google Maps (2016) adaptado pelo autor.

Conforme a Secretaria Municipal de Meio Ambiente, apesar de não haver um plano de arborização urbana, há diversas leis no município que incentivam a doação de mudas de espécies nativas para o plantio de árvores orientado, priorizando as áreas de nascentes ou de mata ciliar. Um exemplo é a Lei no 2.929/12, que dispõe sobre a obrigatoriedade das concessionárias de automóveis no plantio de 
árvores de acordo com as vendas, como um fator para minimizar o impacto causado pelos gases do efeito estufa e Lei no $1.724 / 89$, que dispõe sobre a gratuidade no fornecimento de mudas de plantas ou árvore para os pais de recém-nascidos.

O histórico apresentado da recuperação da mata ciliar demonstra o interesse público e o privado em preservar as margens do Rio Sapucaí para minimizar os impactos causados nos períodos de cheia; como exemplo, as ONGs Projeto Curupira e Projeto Caravelas, com suas ações de replantio de espécies nativas em toda a margem e de educação ambiental na comunidade. Porém, a distância da margem de 50 metros encontra-se em grande parte ocupada, principalmente na área central. Parte desse agravamento foi ocasionado pela tardia implantação do Plano Diretor que garantia a restrição da ocupação do solo e pelos "vazios urbanos" ocasionados por uma ocupação horizontal desigual da cidade. 0 "vazio urbano" pode ser mais bem compreendido como lotes vagos dentro de ocupações existentes que possuem infraestrutura mínima exigida, permitindo, assim, a ocupação desses "vazios" conforme a definição de áreas urbanas consolidadas (Lei no $11.977 / 09$, art. 47ํㅜㄹ ins. II).

As análises de campo, virtual e por meio do SIG permitiram observar que, apesar de respeitar o limite de 15 metros do entorno expresso pela legislação municipal, o Rio Sapucaí encontra-se, em diferentes pontos, em estado de assoreamento. Apesar da reestruturação da mata ciliar, é necessário revitalizar suas margens. Outras obras de grande importância são a futura construção de taludes estruturados em locais críticos, ao longo da extensão do rio, e o desassoreamento, o que poderá permitir maior fluxo de água e evitar enchentes como a ocorrida em 2000, principal motivação para a recuperação da mata ciliar.

\section{Considerações finais}

O estudo mostrou que a implementação do Plano Diretor ao município de Itajubá foi de grande valia quanto à preservação das margens do Rio Sapucaí, criando um zoneamento específico para haver revitalização urbana e melhoria dos serviços à população, como a permissão de ocupação de sistemas viários e equipamentos públicos. Porém, as lacunas existentes obrigam o setor público a recorrer em outras legislações à procura de definições que não são apontadas no Plano, como no caso do conceito de áreas urbanas consolidadas, acarretando incongruências no que é permitido ou não no uso e na ocupação do solo. Essa duplicidade dificulta o controle do adensamento e da expansão urbana, além de não priorizar a revitalização urbana nem do sistema viário em áreas mais adensadas.

A importância do Rio Sapucaí ao município de Itajubá é notória, porém é necessária a revisão do Plano Diretor Municipal e das legislações ambientais municipais para eliminar as lacunas existentes, pois, assim, haverá a possibilidade de um planejamento e controle dos adensamentos das áreas lindeiras ao rio.

Por meio do estudo dos históricos da legislação urbana municipal, é possível compreender as prioridades no adensamento urbano no município, assim como a coerência no uso e na ocupação do solo. Porém, além dos parâmetros urbanísticos, é necessário o cumprimento das diretrizes previstas no Plano Diretor como um todo para se atingir o objetivo de um planejamento urbano sustentável.

\section{Agradecimentos}

Os autores agradecem ao Conselho Nacional de Desenvolvimento Científico e Tecnológico (CNPq), à Fundação de Amparo à Pesquisa do Estado de Minas Gerais (Fapemig) e à Coordenação de Aperfeiçoamento de Pessoal de Nível Superior (Capes) pelo apoio financeiro concedido aos projetos que subsidiaram o desenvolvimento deste trabalho. 


\section{Referências}

Angeoletto, F., Santos, J. W. M. C., Ruiz Sanz, J. P., Silva, F. F., \& Albertín, R. M. (2016). Tipología socio-ambiental de las ciudades medias de Brasil: aportes para un desarrollo urbano sostenible. urbe. Revista Brasileira de Gestão Urbana, 8(2), 272-287. http://dx.doi.org/10.1590/2175-3369.008.002.A008.

Arefiev, N., Terleev, V., \& Badenko, V. (2015). GIS-based fuzzy method for urban planning. Procedia Engineering, 117(1), 39-44. http://dx.doi.org/10.1016/j.proeng.2015.08.121.

Barbosa, A. A., Oliveira, G. M., \& Oliveira, T. J. (2015). Histórico de enchentes em Itajubá-MG. Revista Meio Ambiente e Sustentabilidade, 9(4), 126-140. http://dx.doi.org/10.22292/mas.v9i4.437.

Bispo, T. C., \& Levino, N. A. (2011). Impactos ambientais decorrentes do uso e ocupação desordenada do solo: um estudo da região periférica de Maceió-AL. In Anais do XXXI Encontro Nacional de Engenharia de Produção. Belo Horizonte: ABEPRO. Recuperado em 21 de setembro de 2017, de http://www.abepro.org.br/biblioteca/enegep2011_tn_sto_143_901_18402.pdf

Brasil. (1979, 20 de dezembro). Lei Federal no 6.766, de 19 de dezembro de 1979. Dispõe sobre o parcelamento do solo urbano e dá outras providências. Brasília: Diário Oficial da União. Recuperado em 21 de setembro de 2017, de http://www.planalto.gov.br/CCivil_03/leis/L6766.htm

Brasil. (1988, 5 de outubro). Constituição da República Federativa do Brasil de 1988. Brasília: Diário Oficial da União. Recuperado em 21 de setembro de 2017, de http://www.planalto.gov.br/ccivil_03/constituicao/ConstituicaoCompilado.htm

Brasil. (2001, 11 de julho). Lei no 10.257, de 10 de julho de 2001. Estatuto da cidade. Brasília: Diário Oficial da União. Recuperado em 21 de setembro de 2017, de http://www.planalto.gov.br/ccivil_03/leis/leis_2001/110257.htm

Brasil. (2012, 28 de maio). Lei Federal no 12.651, de 25 de maio de 2012. Código Florestal. Brasília: Diário Oficial da União. Recuperado em 21 de setembro de 2017, de http://www.planalto.gov.br/ccivil_03/_ato20112014/2012/lei/112651.htm

Bressane, A., Stanganini, F. N., Salvador, N. N. B., Rossi, A., \& Viecili, L. G. (2010). Áreas de Preservação Permanente no ambiente Urbano: reflexões sobre os limites da tolerância entre o preservar e o intervir. In Anais do $4^{o}$ Congresso Luso Brasileiro para o Planejamento Urbano, Regional, Integrado, Sustentável. Faro: Universidade de Algarve.

Buhaug, H., \& Urdal, H. (2013). An urbanization bomb? Population growth and social disorder in cities. Global Environmental Change, 23(1), 1-10. http://dx.doi.org/10.1016/j.gloenvcha.2012.10.016.

Câmara, G., Davis, C., \& Monteiro, A. M. V. (2001). Introdução à ciência da geoinformação. São José dos Campos: Instituto Nacional de Pesquisas Espaciais.

Carvalho, S. N. D. (2001). Estatuto da cidade: aspectos políticos e técnicos do plano diretor. São Paulo em Perspectiva, 15(4), 130-135. http://dx.doi.org/10.1590/S0102-88392001000400014.

Cervero, R. B. (2013). Linking urban transport and land use in developing countries. Journal of Transport and Land Use, 6(1), 7. http://dx.doi.org/10.5198/jtlu.v6i1.425.

Google. (2001). Google Earth. Recuperado em 21 de setembro de 2017, de https://www.google.com.br/intl/ptBR/earth/

Google Maps. (2016). Google street view. Recuperado em 21 de setembro de 2017, de http://maps.google.com Guimarães, A. (1987). A história de Itajubá (1. ed). Belo Horizonte: Imprensa Oficial.

Gurgel, R. S., Farias, P. R. S., \& Oliveira, S. N. (2017). Land use and land cover mapping and identification of misuse in the permanent preservation areas in the Tailândia Municipality - PA. Semina: Ciências Agrárias, 38(3), 1145-1160. http://dx.doi.org/10.5433/1679-0359.2017v38n3p1145.

Hassan, A. M., \& Lee, H. (2015). Toward the sustainable development of urban areas: an overview of global trends in trials and policies. Land Use Policy, 48, 199-212. http://dx.doi.org/10.1016/j.landusepol.2015.04.029. 
Honda, S. C. A. L., Vieira, M. C., Albano, M. P., \& Maria, Y. R. (2015). Planejamento ambiental e ocupação do solo urbano em Presidente Prudente (SP). urbe. Revista Brasileira de Gestão Urbana, 7(1), 62-73.

http://dx.doi.org/10.1590/2175-3369.007.001.A004.

Instituto Brasileiro de Geografia e Estatística - IBGE. (2010). Censo demográfico: características da população e dos domicílios. Rio de Janeiro. Recuperado em 21 de setembro de 2017, de http://www.ibge.gov.br/home/

Itajubá. (1991). Lei Municipal no 1774, de 14 de fevereiro de 1991. Dispõe sobre o parcelamento do solo urbano e dá outras providências. Itajubá: Diário Oficial do Município de Itajubá.

Itajubá. (1994). Lei Municipal no 1988. Dispõe sobre revogação e nova redação aos dispositivos legais que indica na Lei Municipal no 1774, de 14 de fevereiro de 1991, de Parcelamento do Solo Urbano, e dá outras providências. Itajubá: Diário Oficial do Município de Itajubá.

Itajubá. (2003). Lei Complementar no 008, I §. Plano Diretor de Desenvolvimento de Itajubá. Itajubá: Diário Oficial do Município de Itajubá.

Kar, R., Obi Reddy, G. P., Kumar, N., \& Singh, S. K. (2018). Monitoring spatio-temporal dynamics of urban and periurban landscape using remote sensing and GIS: a case study from Central India. The Egyptian Journal of Remote Sensing and Space Sciences. http://dx.doi.org/10.1016/j.ejrs.2017.12.006.

Limonad, E., Org, C., Fani, A., Carlos, A., Randolph, R., \& Brandão, C. A. (2014). Um novo planejamento para um novo Brasil? Revista Brasileira de Estudos Urbanos e Regionais, 17(2), 157-159.

Litman, T. (2017). Land use impacts on transport (pp. 1-85). Canada: Victoria Transport Policy Institute. https://doi.org/10.1007/978-3-642-54876-5.

Lombardi, P., \& Ferretti, V. (2015). New spatial decision support systems for sustainable urban and regional development. Smart and Sustainable Built Environment, 4(1), 45-66. http://dx.doi.org/10.1108/SASBE-07-20140039.

Machado, M. H., \& Lima, J. P. (2015). Avaliação multicritério da acessibilidade de pessoas com mobilidade reduzida: um estudo na região central de Itajubá (MG). urbe. Revista Brasileira de Gestão Urbana, 7(3), 368-382.

http://dx.doi.org/10.1590/2175-3369.007.003.A008.

Maricato, E. (2006). O Ministério das Cidades e a política nacional de desenvolvimento urbano: políticas sociais: acompanhamento e análise. Brasília: Ipea. Recuperado em 21 de setembro de 2017, de https://www.ipea.gov.br/agencia/images/stories/PDFs/politicas_sociais/ensaio2_ministerio12.pdf

Mehra, M., Singh, C. K., Abrol, I. P., \& Oinam, B. (2017). A GIS-based methodological framework to characterize the Resource Management Domain (RMD): a case study of Mewat district, Haryana, India. Land Use Policy, 60, 90-100. http://dx.doi.org/10.1016/j.landusepol.2016.10.018.

Mello, A., \& Portugal, L. (2017). Um procedimento baseado na acessibilidade para a concepção de planos estratégicos de mobilidade urbana: o caso do Brasil. EURE. Revista Latinoamericana de Estudios Urbano Regionales, 43(128), 99-125. http://dx.doi.org/10.4067/S0250-71612017000100005.

Minas Gerais. (1991). Lei Estadual no 10.561, de 27 de dezembro de 1991. Dispõe sobre a política florestal no Estado de Minas Gerais. Belo Horizonte: Diário do Executivo.

Moscarelli, F., \& Kleiman, M. (2017). Os desafios do planejamento e gestão urbana integrada no Brasil: análise da experiência do Ministério das Cidades. urbe. Revista Brasileira de Gestão Urbana, 9(2), 157-171. http://dx.doi.org/10.1590/2175-3369.009.002.ao01.

Nasri, A., \& Zhang, L. (2014). The analysis of transit-oriented development (TOD) in Washington, D.C. and Baltimore metropolitan areas. Transport Policy, 32, 172-179. http://dx.doi.org/10.1016/j.tranpol.2013.12.009.

Netto, V. M., \& Krafta, R. (2009). A forma urbana como problema de desempenho: o impacto de propriedades espaciais sobre o comportamento urbano. Revista Brasileira de Estudos Urbanos e Regionais, 11(2), 157-180. http://dx.doi.org/10.22296/2317-1529.2009v11n2p157. 
Requia, W. J., Roig, H. L., Koutrakis, P., \& Rossi, M. S. (2016). Mapping alternatives for public policy decision making related to human exposures from air pollution sources in the Federal District, Brazil. Land Use Policy, 59, $375-385$. http://dx.doi.org/10.1016/j.landusepol.2016.09.017.

Rolnik, R. (2009). Democracia no fio da navalha: limites e possibilidades para a implementação de uma agenda de Reforma Urbana no Brasil. Revista Brasileira de Estudos Urbanos e Regionais, 11(2), 31-50. http://dx.doi.org/10.22296/2317-1529.2009v11n2p31.

Sakamoto, E., \& Lima, J. P. (2016). Acessibilidade em ambiente rural: uma abordagem multicritério com uso de SIG. Transportes, 24(1), 63-73. http://dx.doi.org/10.14295/transportes.v24i1.958.

Sánchez-Lozano, J. M., \& Bernal-Conesa, J. A. (2017). Environmental management of Natura 2000 network areas through the combination of Geographic Information Systems (GIS) with Multi-Criteria Decision Making (MCDM) methods: case study in south-eastern Spain. Land Use Policy, 63, 86-97. http://dx.doi.org/10.1016/j.landusepol.2017.01.021.

Silva, A. N. R., Costa, M. S., \& Macedo, M. H. (2008). Multiple views of sustainable urban mobility: The case of Brazil. Transport Policy, 15(6), 350-360. http://dx.doi.org/10.1016/j.tranpol.2008.12.003.

Waddell, P. (2011). Integrated land use and transportation planning and modelling: addressing challenges in research and practice. Transport Reviews, 31(2), 209-229. http://dx.doi.org/10.1080/01441647.2010.525671.

Wan, L., Ye, X., Lee, J., Lu, X., Zheng, L., \& Wu, K. (2015). Effects of urbanization on ecosystem service values in a mineral resource-based city. Habitat International, 46, 54-63. http://dx.doi.org/10.1016/j.habitatint.2014.10.020.

Editor: Harry Bollmann

Recebido: Set. 21, 2017

Aprovado: Abr. 23, 2018 